\title{
Could infrared thermal imaging be a new diagnostic tool for acute appendicitis?
}

\author{
Sinan Hatipoglu ${ }^{1, A-F}$, Ruslan Abdullayev ${ }^{2, D, F}$ \\ 1 Department of General Surgery, Faculty of Medicine, Adıyaman University, Turkey \\ ${ }^{2}$ Department of Anesthesiology and Reanimation, Adıyaman University Research and Educational Hospital, Turkey \\ A - research concept and design; $\mathrm{B}$ - collection and/or assembly of data; $\mathrm{C}$ - data analysis and interpretation; \\ $D$ - writing the article; $E$ - critical revision of the article; $F$ - final approval of the article
}

\section{Address for correspondence \\ Sinan Hatipoglu \\ E-mail: hamitsinanh@gmail.com}

\section{Funding sources}

This study received financial support as an individual research project from Adiyaman University, Turkey (Project No: TIPBAP/2012-0004).

\section{Conflict of interest}

None declared

\section{Acknowledgements}

The authors want to thank Assoc. Prof. Dr. Bulent Celik for statistical analysis and interpretation of data.

Received on September 23, 2016 Reviewed on January 12, 2017 Accepted on March 21, 2018

Published online on January 17, 2019

\begin{abstract}
Background. Appendicitis is the most frequent acute abdominal disease and there are actual effective diagnostic tools for its detection.

Objectives. The objective of this study was to determine whether a thermal imaging camera is a useful tool for diagnosing acute appendicitis on the basis of abdominal skin surface temperature changes which reflect intra-abdominal inflammation.

Material and methods. The prospective data consisting of surgical and pathological findings of 51 patients who had undergone appendectomy between January 2013 and December 2014 with the diagnosis of acute appendicitis was collected, as well as thermal imaging camera recordings. A handheld infrared (IR) thermal imaging camera (ITIC) was used to take measurements.

Results. Of the 51 patients studied, 30 were male and 21 were female. Of these, 12 had their highest temperature measurement in the epigastric and 17 in the umbilical areas. These 2 groups constituted $56.9 \%$ of the patients. Regarding the lowest temperature measurement, 10 patients had the lowest temperature in the right inguinal and 15 in the hypogastric area. These 2 numbers constituted $49 \%$ of the patients.

Conclusions. This is the first report concerning the use of a thermal camera as a diagnostic tool for the evaluation of acute abdominal illness. Considering the results of our study, ITIC is not feasible as a new diagnostic tool for acute appendicitis. It may be suitable for determining superficial inflammation; however, it is not suitable for determining deep inflammation.
\end{abstract}

Key words: acute appendicitis, diagnostic tool, thermal camera, infrared imaging, acute inflammation

Cite as

Hatipoglu S, Abdullayev R. Could infrared thermal imaging be a new diagnostic tool for acute appendicitis? Adv Clin Exp Med. 2019;28(3):361-367. doi:10.17219/acem/87114

DOI

10.17219/acem/87114

\section{Copyright}

Copyright by Author(s)

This is an article distributed under the terms of the

Creative Commons Attribution Non-Commercial License

(http://creativecommons.org/licenses/by-nc-nd/4.0/) 


\section{Background}

All the objects over $-273^{\circ} \mathrm{C}(0 \mathrm{~K})$ emit thermal energy with an infrared (IR) wavelength. This radiation is proportional to the vibration and rotation of the molecules of the object. The amount of radiation is proportional to the fourth power of the temperature; hence, minor changes in the temperature result in substantial changes in the amount of radiation. ${ }^{1,2}$ This observation has given rise to the concept of observing IR radiation as an indicator of the temperature changes. Infrared radiation is invisible to the naked eye, which is why thermal cameras are used for visualization.

A thermal camera is a device that senses the thermal model of an object in the IR wavelength spectrum, without physical contact. It consists of an optical mechanical unit, detector and processing unit. A lens collects the IR light and focuses it on an IR detector, after which the processing unit creates an electronic image. This image contains a color spectrum from blue to yellow according to the temperature, where blue represents the coldest area and yellow the hottest (Fig. 1). Infrared thermography (IRT) has been used for many years in the military, aerospace research, construction industry, textile field, other industrial sectors, and veterinary medicine. ${ }^{3,4}$ Although its use in medicine dates back to $1960 \mathrm{~s}$, it has only recently gained popularity. ${ }^{5}$ With the technological developments in IRT, it is increasingly being used in many fields of medicine for diagnostic purposes. ${ }^{3,6}$

Abdominal pain constitutes $4-8 \%$ of adult admissions to the emergency surgery service, and appendicitis is the most frequently considered diagnosis among these cases. ${ }^{7}$ Suspicion of appendicitis is one of the most common results of surgical consultations in the outpatient or emergency room setting. Late diagnosis is associated with increased risk of morbidity and mortality, which is why early diagnosis is crucial. ${ }^{7,8}$ The diagnosis of appendicitis is based on clinical examination, laboratory findings and abdominal ultrasonography (USG). Scoring systems, abdominal X-ray, computed tomography (CT), magnetic resonance imaging (MRI), and diagnostic laparoscopy are also used in the diagnosis. ${ }^{7,8}$ These diagnostic instruments have different advantages and disadvantages as well as specificity and sensitivity.

The aim of this study was to analyze abdominal wall IR thermal images of patients with intra-abdominal inflammation and evaluate if this method could be a good diagnostic tool for acute appendicitis.

\section{Material and methods}

A total of 51 patients undergoing emergency appendectomy under general anesthesia at the Department of General Surgery of Adiyaman University Research and Educational Hospital, Turkey, between January 2013 and December 2014 were recruited into the study. The Clinical Trials Ethics Committee of Adryaman University approval was obtained. Prospective data of the patients consisting of surgical

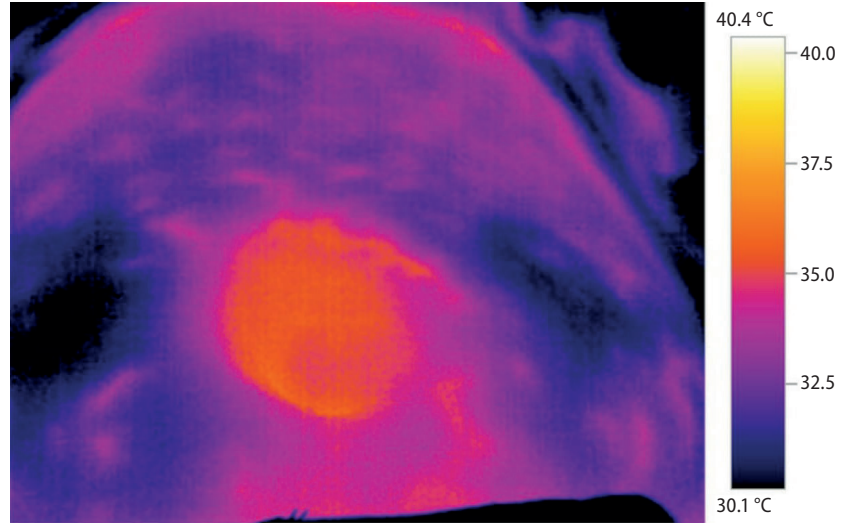

Fig. 1. Thermal camera images contain a color spectrum from blue to yellow according to the temperature, where blue represents the coldest area and yellow the hottest

and pathological findings was collected, as well as thermal camera images. The research adhered to the tenets of the Declaration of Helsinki and informed consent was obtained from all patients.

The data consisted of the first findings obtained at admission and included body temperature, preoperative thermal imaging camera observations of abdominal skin surface, perioperative, and pathological findings. Acute appendicitis was diagnosed by history and physical examination, as well as laboratory and radiological examinations, and then thermal camera images of anterior abdominal skin surface were taken preoperatively. Thermal camera images were co-evaluated with operational data and histopathological findings.

Preoperative surgical evaluation of the patients included serum electrolyte levels, standard liver function tests, enzymes, complete blood count, coagulation tests, serology tests for HIV and hepatitis B and C viruses, electrocardiography, and chest radiography. ${ }^{7,8}$ Emergency USG and CT imaging were not routinely performed in these patients due to an insufficient access to radiological consultation out-ofshift. The first examination and surgery in these patients were performed by the same general surgeon. The patients received preoperatively a prophylactic dose of $2^{\text {nd }}$ generation cephalosporin (1 g iv.) and underwent an open approach appendectomy via a McBurney incision under general anesthesia. ${ }^{7}$ A laparoscopic approach was not performed due to technical inadequacy. Diagnosis of appendicitis was made by perioperative macroscopic evaluation. All microscopic evaluations of appendectomy specimens from patients were evaluated in the hospital pathology unit. Histopathologically negative appendectomy specimens for appendicitis were excluded from the study.

\section{Application and properties of infrared thermal imaging}

A number of factors were standardized to minimize variability, including pre-measurement time lag, patient positioning, camera distance, room temperature, 
and humidity. The patients were transported to the operation room $10 \mathrm{~min}$ before the measurement to give time for temperature equilibration between core and skin. The patients were placed in supine position and anteroposterior IR images were obtained with thermal cameras placed $30 \mathrm{~cm}$ from the patient's abdominal wall. Images were obtained in the room shielded from direct sunlight. Temperature was kept between $20^{\circ} \mathrm{C}$ and $22^{\circ} \mathrm{C}$, and humidity between $40 \%$ and $60 \%$. We used a handheld IR thermal camera (Testo 882; Testo Electronics and Thermal Imaging Systems, Istanbul, Turkey) with a resolution of $320 \times 240$ pixels and thermal sensitivity $<0 \mathrm{mK}$ (i.e., temperature changes of $0.05^{\circ} \mathrm{C}$ were detected). Thermal maps of the abdominal wall were recorded and the data was stored, after which it was analyzed by dividing the abdominal wall into 9 quadrants (right hypochondriac, epigastric,
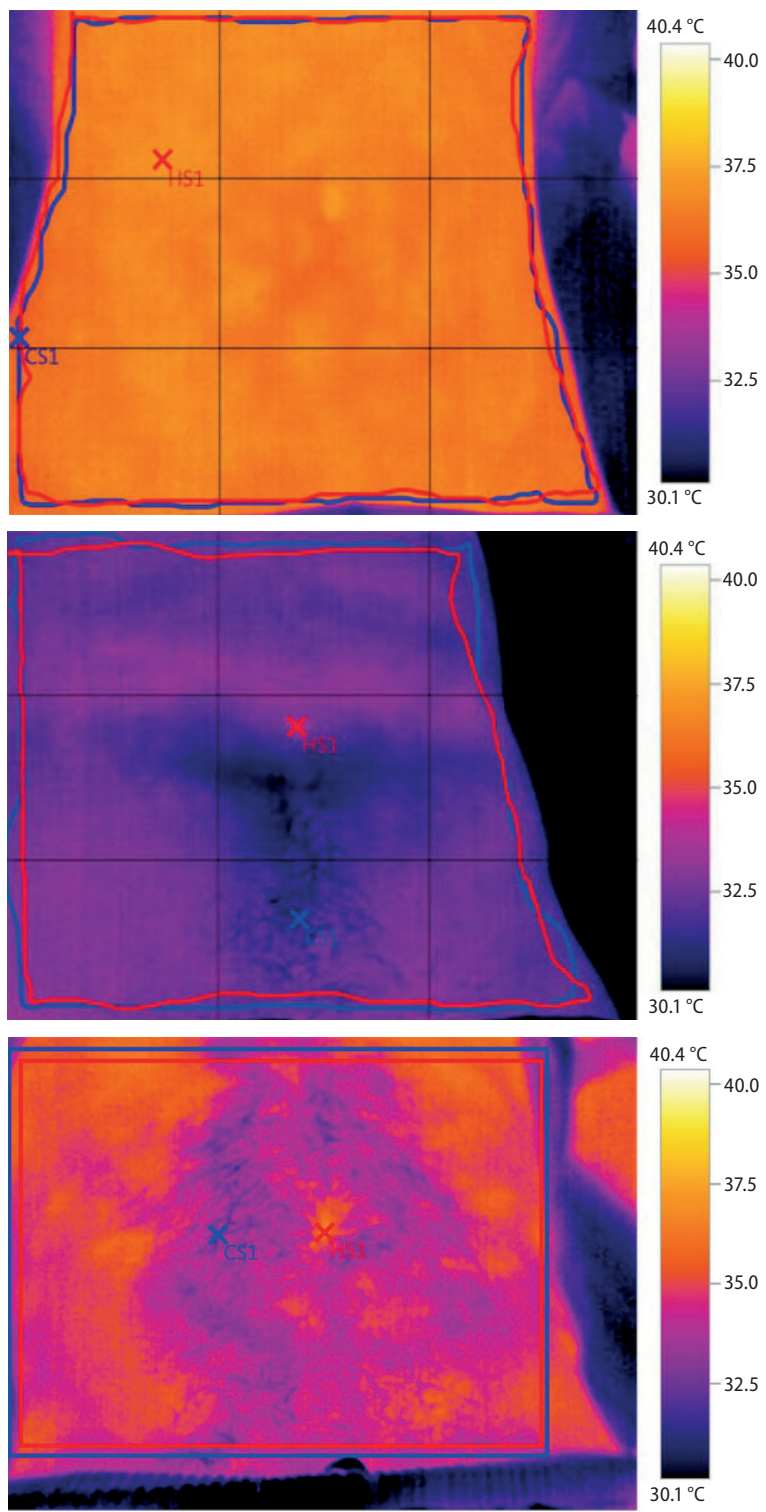

Fig. 2. Abdominal wall quadrants (right hypochondriac, epigastric, left hypochondriac, right lumbar, umbilical, left lumbar, right iliac, hypogastric, and left iliac) and minimum and maximum temperatures from the thermal maps (CS: Coldest Spot, HS: Hottest Spot) left hypochondriac, right lumbar, umbilical, left lumbar, right iliac, hypogastric, and left iliac), and extracting minimum and maximum temperature values from the thermal maps as indicated in Fig 2. Figure 3 presents an example of the thermal map of one of the patients.

\section{Statistical analysis}

Data analysis was performed using Statistical Package for the Social Sciences v. 15.0 (SPSS Inc., Chicago, USA). Highest and lowest temperature values in respective areas were presented as mean, standard deviation (SD), and minimum and maximum values. Also, the frequency and percentages of temperature measurements obtained from the areas are presented in the Tables 1 and 2 . The data was interpreted using these percentages, means and SDs.

\section{Results}

Fifty-one consecutive open appendectomies were performed during the study period. All of the patients were classified using American Society of Anesthesiologists (ASA) physical fitness classification system as I-II E. The mean age was $27.4 \pm 7.5$ years (range: $18-55$ years); 21 of the patients were women, whereas 30 were men.

Tables 1 and 2 present the highest and lowest temperature measurements of the abdominal wall regions. Of these 51 patients, 12 had their highest temperature measurement in the epigastric and 17 in the umbilical

Table 1. Regions of the abdomen with highest temperature values

\begin{tabular}{|l|c|c|c|c|c|c|}
\hline \multirow{2}{*}{ Areas } & \multirow{2}{*}{$\mathrm{n}$} & \multirow{2}{*}{$\%$} & \multicolumn{5}{|c|}{ Temperature } \\
\cline { 5 - 8 } & & & mean & SD & min & max \\
\hline Right hypochondrium & 8 & 15.7 & 36.9 & 1.1 & 35.1 & 38.4 \\
\hline Epigastric region & 12 & 23.5 & 36.8 & 1.1 & 34.9 & 39.2 \\
\hline Left hypochondrium & 2 & 3.9 & 37.3 & 1.3 & 36.3 & 38.2 \\
\hline Umbilical region & 17 & 33.3 & 36.6 & 1.0 & 34.1 & 38.0 \\
\hline Hypogastric region & 6 & 11.8 & 36.1 & 1.0 & 34.7 & 37.6 \\
\hline Left inguinal region & 6 & 11.8 & 36.2 & 1.4 & 34.3 & 38.0 \\
\hline
\end{tabular}

Table 2. Regions of the abdomen with lowest temperature values

\begin{tabular}{|l|c|c|c|c|c|c|}
\hline \multicolumn{1}{|c|}{ Areas } & \multirow{2}{*}{$\mathrm{n}$} & $\%$ & \multicolumn{5}{|c|}{ Temperature } \\
\cline { 5 - 8 } & & & mean & SD & min & max \\
\hline Right hypochondrium & 5 & 9.8 & 33.1 & 1.6 & 31.1 & 35.4 \\
\hline Left hypochondrium & 2 & 3.9 & 32.1 & 0.3 & 31.9 & 32.3 \\
\hline Right colic region & 9 & 17.6 & 33.5 & 2.0 & 30.1 & 35.3 \\
\hline Umbilical region & 1 & 2.0 & 30.9 & 0.0 & 30.9 & 30.9 \\
\hline Left colic region & 1 & 2.0 & 34.7 & 0.0 & 34.7 & 34.7 \\
\hline Right inguinal region & 10 & 19.6 & 33.4 & 1.9 & 29.8 & 35.5 \\
\hline Hypogastric region & 15 & 29.4 & 32.6 & 1.6 & 30.0 & 35.4 \\
\hline Left inguinal region & 8 & 15.7 & 32.3 & 1.4 & 30.8 & 34.3 \\
\hline
\end{tabular}




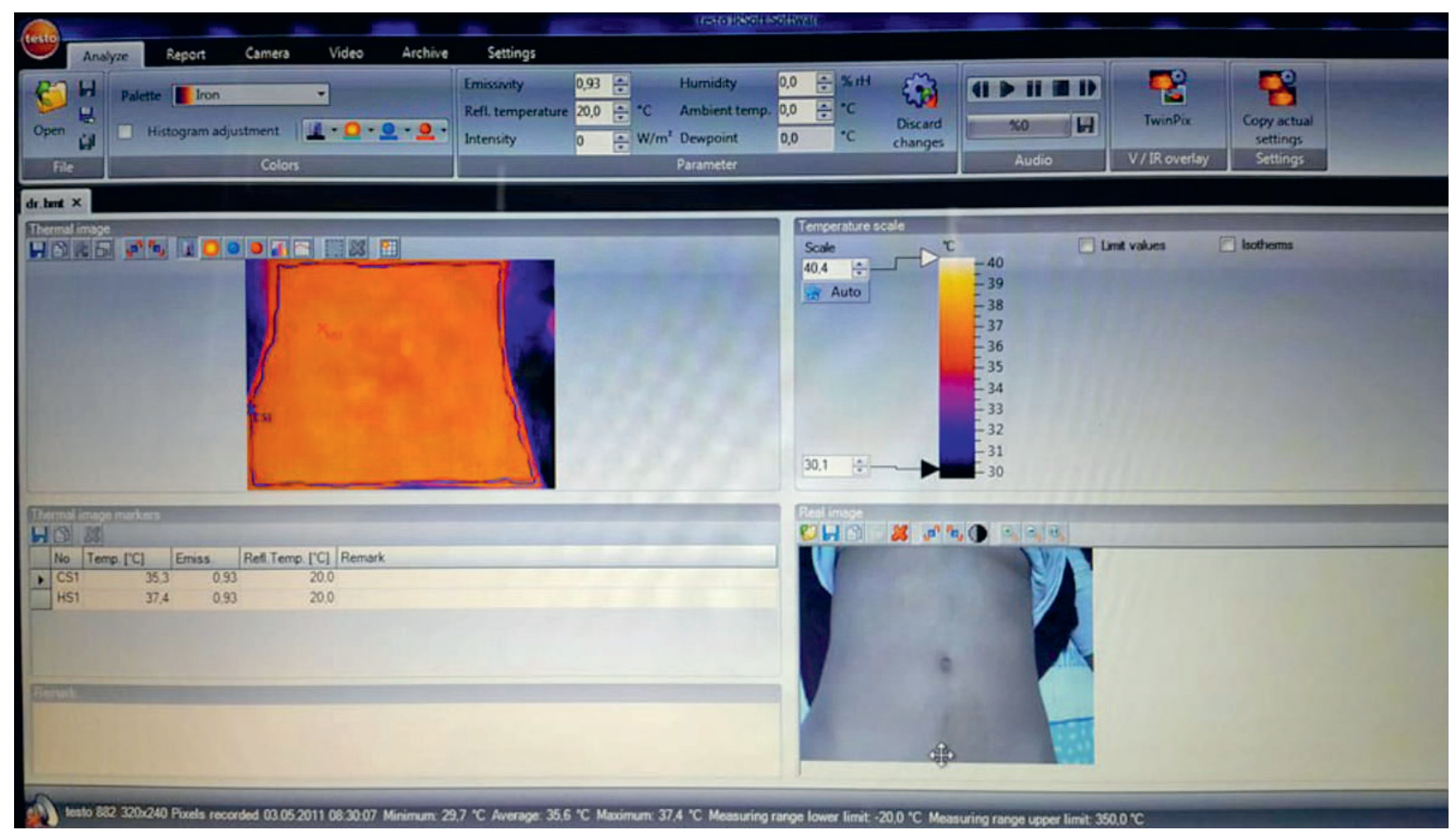

Fig. 3. An example of the thermal screen of infrared thermal imaging obtained from one of the patients

areas. These 2 groups constituted $56.9 \%$ of the patients. Regarding the lowest temperature measurement, 10 patients had their lowest temperature measurements in the right inguinal and 15 in the hypogastric area. These 2 groups constituted $49.0 \%$ of the patients.

\section{Discussion}

The main finding of our study was that IR thermal imaging of abdominal wall in the patients with acute appendicitis does not help in precise diagnosis of this disease. The temperature of the abdominal wall skin does not reveal deeper pathologies.

Infrared thermal imaging becomes more and more common diagnostic technique in medicine. It is used for diagnostic purposes in veterinary medicine. ${ }^{9,10}$ Its use in medicine comprises the evaluation of side effects and the reliability of surgical devices and procedures, ${ }^{11-15}$ animal experiments ${ }^{16}$ and, of course, diagnostic purposes. Carpal tunnel syndrome, varicocele, thyroid diseases, breast cancer, diabetic wounds, surgical site infections, compartment syndrome, and rheumatic diseases are diagnosed using this technique, among others. ${ }^{1,17-23}$

Infrared thermal imaging is a non-invasive, painless assessment tool. Its non-invasive nature makes it convenient for serial measurements. Minor changes in the temperature, even as small as $0.01^{\circ} \mathrm{C}$, can be detected. It can give objective information about pain. The physiological structure of the investigated area is observed rather than the anatomical, and thermal map of the region can be generated. Real time assessment is another advantage of this method. ${ }^{6}$ Thermal cameras can only sense superficial temperature, so measurements can only be made beyond 1-2 $\mathrm{mm}$ of the epidermis. ${ }^{24}$ The advantages of thermal camera as a diagnostic tool besides its non-invasive nature are its ease of application, non-subjective results, costeffectiveness, and the fact that it can be applied by every physician and/or specialist staff. Also, it is a temperature measuring technique, capable of displaying real-time surface temperature distribution and measuring a wide range of temperature on the macro as well as on the micro levels.

Microcirculation and thermal radiation in human tissue are influenced by inflammatory, metabolic and toxic factors, and are mediated through sympathetic tonus and vasoactive agents. ${ }^{25}$ Many pathological processes manifest themselves as local changes in heat production and also as changes in blood flow pattern in affected organs or tissues. Owing to the blood flow and conductive transfer of heat from the interior of the body to the surface areas, IR images are believed to be capable of reflecting thermal processes deep in the body. ${ }^{26}$ Despite standard measurements like flow and resistance, IRI can also provide data about homogeneity of blood flow in the organs. ${ }^{27}$

Acute appendicitis is an acute inflammatory condition resulting from early response of appendicular tissue to injury. Acute inflammation is non-specific and may be evoked by any injury. ${ }^{28}$ It is a short-term process, occurring before the immune response becomes established, usually appearing within few minutes or hours and ceasing upon 

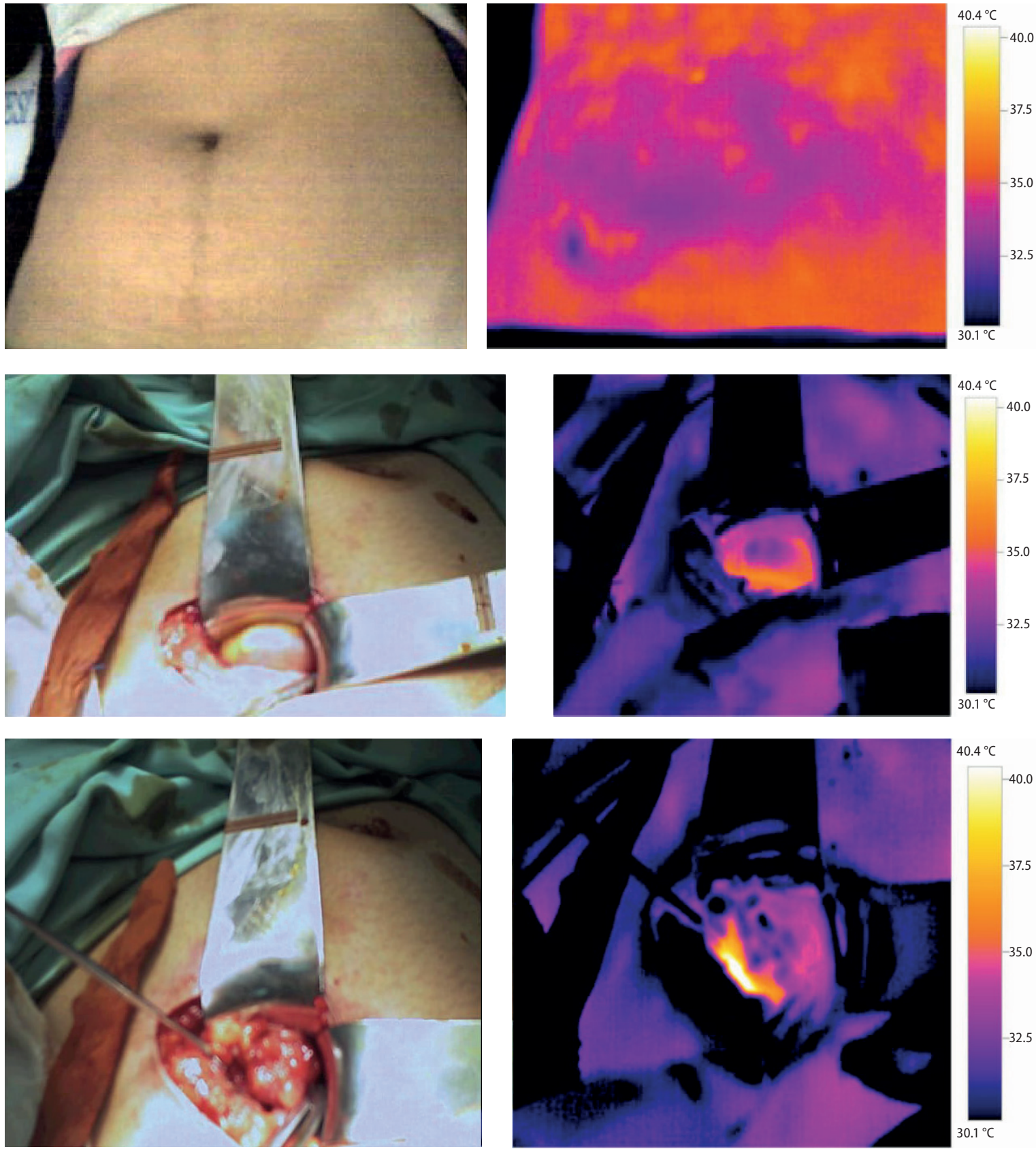

Fig. 4. This preoperative and peroperative examination was carried out according to EN 13187 using a thermal image from one of the patients' respectively Picture parameters: Emissivity: 0.93; Refl. temp. [ $\left.{ }^{\circ} \mathrm{C}\right]: 20.0$; Lens: Standard $32^{\circ}$

the removal of the injurious stimulus. Acute inflammation may be regarded as the first line of defense against tissue injury and is characterized by changes in the microcirculation, exudation of fluid and emigration of leukocytes from blood vessels to the area of injured tissues. ${ }^{28}$ Acute inflammation normally resolves by mechanisms still remaining somewhat elusive. ${ }^{29}$ Physical examination, laboratory tests and radiological evaluations are being carried out during the diagnosis of acute appendicitis. ${ }^{7,8}$ Sometimes USG and CT examinations are mandatory for proper diagnosis, yet subjective interpretations may yield some problems. The purpose of this study was to evaluate IRI as an alternative to other radiodiagnostic tools in the diagnosis of acute appendicitis. The hypothesis was based on the possible abdominal skin wall temperature changes after intra-abdominal inflammatory process (Fig. 4).

Clinically, acute inflammation is characterized by 5 cardinal signs: rubor (redness), color (increased heat), tumor (swelling), dolor (pain), and functio laesa (loss of function). ${ }^{28}$ The first 4 were described by Celsus; the $5^{\text {th }}$ was a later addition by Virchow and these 5 signs are manifested when acute inflammation occurs on the surface of the body, but not all of them may be apparent in acute inflammation of internal organs. ${ }^{28}$ 
The increased heat of inflamed skin is due to the entry of a large amount of blood at body core temperature into the naturally cooler skin. When inflammation occurs internally - where tissue is normally at body core temperature - no increase in heat is apparent. ${ }^{28}$ On the other hand, it is not clear whether there is a meaningful temperature increase on the abdominal skin surface because of the acute appendicitis. A thorough understanding of the physiology of the acute inflammation of appendix is essential. Some questions must be addressed. Is there a meaningful increase in the temperature of local inflammation area? How can this temperature change be reflected in the abdominal skin? How can we precisely measure it? Is it possible that detection of this local temperature increase can be helpful for the diagnosis of acute abdominal disease, especially for acute appendicitis? There are no studies in the literature regarding the use of a thermal imaging camera. Therefore, we aimed to find answers to these questions.

About $57 \%$ of the patients had their highest temperature values recorded in the epigastric and umbilical areas. None of the patients had their highest temperature recordings in their right inguinal area. Even though our initial expectations were that the highest temperature recordings would be found in the right inguinal area, about half of the patients had the lowest temperature measurements in their right inguinal and hypogastric areas. Anatomical proximity of the large vessels and abdominal skin wall thicknesses can be an explanation.

Temperature changes in the inflammation area can be recorded using deep tissue thermal cannula. Sasaki used subdermal thermal cannula for comparison of subdermal tissue temperature with skin temperature. ${ }^{12}$ Further studies should be devoted to this method. A possible positive correlation between deep and superficial temperature can lead to a hypothesis about the thermal conduction. Temperature changes in the skin due to blood flow are complex and will follow vascular anatomy. Moreover, a minimal temperature increase on the abdominal skin surface may be precisely determined with the development of medical technology and technological advances in devices such as non-invasive thermal imaging camera.

There were several limitations in this study. Optimal time for obtaining IR image is not clearly determined, so we took IR images of the patients after a 10-minute waiting period in the operation room. Ring has proposed a 15-minute waiting time for temperature equilibration between skin and body core. ${ }^{6}$ Nonetheless, the time was standardized for all the patients. Another limitation was the lack of data record and standardization of the patients' body mass index (BMI). Taking into consideration possible temperature conduction from deeper tissues besides blood flow, patients with a thick abdominal wall will have different conductive properties compared to patients with a lower BMI. Intra-abdominal or subdermal temperature measurements via cannulas could have been made for the sake of comparison, as done by Sasaki. ${ }^{12}$ Because of the limited technical capacity of the camera used in our study, temperature differences below $0.05^{\circ} \mathrm{C}$ could not have been detected and the low resolution of the camera was another shortcoming.

In conclusion, IR thermal imaging does not meet the requirements for a good diagnostic tool for acute appendicitis. Despite its significance in many areas of medicine, its usefulness in acute intra-abdominal inflammation is limited because of its inability to evaluate the body's interior. However, this method might be promising if temperature changes in deeper tissues are visualized with improved technology.

\section{References}

1. Trum JW, Gubler FM, Laan R, van der Veen F. The value of palpation, varicoscreen contact thermography and colour Doppler ultrasound in the diagnosis of varicocele. Hum Reprod. 1996;11(6):1232-1235.

2. Hovinen M, Siivonen J, Taponen S, et al. Detection of clinical mastitis with the help of a thermal camera. J Dairy Sci. 2008;91(2):4592-4598.

3. Knobel RB, Guenther BD, Rice HE. Thermoregulation and thermography in neonatal physiology and disease. Biol Res Nurs. 2011;13(3):274-282.

4. Gowen A, Tiwari B, Cullen P, McDonnell K, O'Donnell C. Applications of thermal imaging in food quality and safety assessment. Trends Food Sci Tech. 2010;21(4):190-200.

5. Wolfe WL. Infrared imaging devices in infrared medical radiography. Ann N Y Acad Sci. 1964;121:57-70.

6. Ring F. Thermal imaging today and its relevance to diabetes. J Diabetes Sci Technol. 2010;4(4):857-862.

7. Hatipoglu S, Hatipoglu F, Abdullayev R. Acute right lower abdominal pain in women of reproductive age: Clinical clues. World J Gastroenterol. 2014;20(14):4043-4049.

8. Hatipoglu S, Hatipoglu F, Akbulut S, Abdullayev R. Management of acute appendicitis in pregnancy: Early diagnosis and early surgery! Sylwan. 2014;158(7):16-35.

9. Malafaia O, Brioschi ML, Aoki SM, et al. Infrared imaging contribution for intestinal ischemia detection in wound healing. Acta Cir Bras. 2008;23(6):511-519.

10. Cetinkaya MA, Demirutku A. Thermography in the assessment of equine lameness. Turk J Vet Anim Sci. 2012;36:43-48.

11. Phillips CK, Hruby GW, DurakE, et al. Tissue response to surgical energy devices. Urology. 2008;71(4):744-748.

12. Sasaki GH. Quantification of human abdominal tissue tightening and contraction after component treatments with 1064-nm/1320$\mathrm{nm}$ laser-assisted lipolysis: Clinical implications. Aesthet Surg J. 2010; 30(2):239-245.

13. Ryoo NK, Kwon JW, Wee WR, Miller KM, Han YK. Thermal imaging comparison of Signature, Infiniti, and Stellaris phacoemulsification systems. BMC Ophthalmol. 2013;13:53.

14. Cutti AG, Perego P, Fusca MC, Sacchetti R, Andreoni G. Assessment of lower limb prosthesis through wearable sensors and thermography. Sensors (Basel). 2014;14(3):5041-5055.

15. Baker R, Whitehouse M, Kilshaw M, et al. Maximum temperatures of $89^{\circ} \mathrm{C}$ recorded during the mechanical preparation of 35 femoral heads for resurfacing. Acta Orthop. 2011;82(6):669-673.

16. Sugimoto S, Nakajima $\mathrm{H}$, Kodo K, et al. Miglitol increases energy expenditure by upregulating uncoupling protein 1 of brown adipose tissue and reduces obesity in dietary-induced obese mice. Nutr Metab (Lond). 2014;11:14.

17. Bilir A, Gülec $S$, Ekemen $S$. Karpal tünel sendromu düşünülen bir gebede termografi kullanımı. Osmangazi Tip Dergisi. 2015;27:91-96.

18. Helmy A, Holdmann M, Rizkalla M. Application of thermography for non-invasive diagnosis of thyroid gland disease. IEEE Trans Biomed Eng. 2008;55(3):1168-1175.

19. Bharara M, Cobb JE, Claremont DJ. Thermography and thermometry in the assessment of diabetic neuropathic foot: A case for furthering the role of thermal techniques. Int J Low Extrem Wounds. 2006;5(4):250-260. 
20. Katz LM, Nauriyal V, Nagaraj S, et al. Infrared imaging of trauma patients for detection of acute compartment syndrome of the leg. Crit Care Med. 2008;36(6):1756-1761.

21. Fujita K, Noguchi M, Yuzuriha S, Yanagisawa D, Matsuo K. Usefulness of infrared thermal imaging camera for screening of postoperative surgical site infection after the Nuss procedure. Case Rep Surg. 2013;2013:946156.

22. Azharuddin M, Bera SK, Datta H, Dasgupta AK. Thermal fluctuation based study of aqueous deficient dry eyes by non-invasive thermal imaging. Exp Eye Res. 2014;120:97- 102.

23. Romano CL, Logoluso N, Dell'Oro F, Elia A, Drago L. Telethermographic findings after uncomplicated and septic total knee replacement. Knee. 2012;19(3):193-197.

24. Braverman IM. The cutaneous microcirculation. J Investig Dermatol Symp Proc. 2000;5(1):3-9.
25. Bonelli RM, Koltringer P. Autonomic nervous function assessment using thermal reactivity of microcirculation. Clin Neurophysiol. 2000; 111(10):1880-1888

26. Vainer BG. FPA-based infrared thermography as applied to the study of cutaneous perspiration and stimulated vascular response in humans. Phys Med Biol. 2005;50(23):R63-94.

27. Gorbach $A M$, Leeser DB, Wang $H$, et al. Assessment of cadaveric organ viability during pulsatile perfusion using infrared imaging. Transplantation. 2009;87(8):1163-1166.

28. Chandrasoma P, Taylor CR. The Acute Inflammatory Response, subsection Cardinal Clinical Signs (Chapter 3). The Host Response to Injury (Section II.), General Pathology (Part A), (3 ${ }^{\text {rd }}$ edition (Computer file) ed.). New York, NY: McGraw-Hill; 2015.

29. Serhan CN, Savill J. Resolution of inflammation: The beginning programs the end. Nat Immunol. 2005;6(12):1191-1197. 